\title{
Evaluation and Analysis of High Quality Economic Development Indicators by the Analytic Hierarchy Process Model
}

\author{
Guoqiang Wang (iD \\ School of Management, Northwestern Polytechnical University, Xi'an, Shanxi 710072, China \\ Correspondence should be addressed to Guoqiang Wang; wangguoqiang1983@mail.nwpu.edu.cn
}

Received 25 November 2021; Revised 28 December 2021; Accepted 3 January 2022; Published 18 January 2022

Academic Editor: Sikandar Ali

Copyright ( $\odot 2022$ Guoqiang Wang. This is an open access article distributed under the Creative Commons Attribution License, which permits unrestricted use, distribution, and reproduction in any medium, provided the original work is properly cited.

\begin{abstract}
The extensive and unsustainable economic development has seriously hindered the friendly development of the economy. The economy pays more attention to the quality and quality of development and needs a way to evaluate economic development objectively. The study puts forward four first-level indicators and 12 second-level indicators for high-quality economic development, which can be evaluated from the essence of economic development. The initial stage is to construct the model structure, with high-quality economic development as the higher level and economic structure and green development as the middle levels of the analytic hierarchy process (AHP); to construct the matrix and introduce secondary indicators; to calculate the maximum eigenvalue; and to analyze and evaluate. In the example, the economic development quality of a region is evaluated, and the corresponding quality membership degree is higher, which belongs to the better development quality. The hierarchical development model proposed in this paper can better evaluate the lack of development power due to the imbalance of economic development and environmental factors and fundamentally realize the fair and just evaluation of the process of economic development.
\end{abstract}

\section{Introduction}

As the development goal of today's society, economic development is more related to the lives of every common citizen. With high-quality economic development, people's living standards can be improved. From the reform and opening up of the Third Plenary Session of the Eleventh Central Committee to the 19th National Congress of the Communist Party of China, China has formed a relatively complete economic system. Economic development requires the cooperation of multiple parties, the support of national policies, the hard work of the public, the production efficiency of enterprises, professional knowledge and skills, and patented technologies. After studying some foreign language documents, it is not difficult to find that the economic development processes of foreign countries are hundreds of years earlier than China's. There is no doubt that in this same process, starting from the perspective of finding the law, there is indeed a lot of experience worth learning. Yaksic [1] and Nekrep et al. [2] rely on national comprehensive investment funds for research and development to promote economic growth and facilitate leapfrog development. Other studies by Lezgovko and Lezgovko [3] have shown that obtaining a small portion of $\mathrm{R}$ and $\mathrm{D}$ funding will greatly help EU countries achieve their economic goals. Tsaurai and Do [4] changed the traditional ways of entrepreneurship in the past, using new technologies and innovative ways to start a business to promote economic growth. It also improves the quality of economic development. Another example is in the inner circle of the economy [5], solving the world's problems. Use human resources and the cultural environment to improve the known problems in the process of economic development. In the same external factors, the layout of the city and the location of the city cannot be ignored. Just as Douglas and Muller [6] consider the deployment plan and the location of the population size and development trajectory of the urban area, as well as the basic factors of urban competition: human resources and cultural environment. SWOT analysis methods are combined to determine the central location of the city. To a large extent, the 
development of science and technology has enabled the use of professional technology to more scientifically judge the factors that affect the development of economic quality. This further improved the priority competitiveness of the country. Zanakis and Becerra-Fernandez [7] and Paul and Gert-Jan [8] studies report that the economic development process is also monitored through digital models to compare the degree of influence of national policies on the urban development process. Social research cannot be ignored in the study of economic development. For example, the research conducted by Barro [9] and Mlachila [10] involves the analysis of multiple behavioral results. If multiple factors are similar, it is difficult to judge whether a single part of the income has an impact on other results without the experimental data. After Chorianopoulos et al. [11] studied the impact of space adaptation on urban competition and the process of competition, the development of the Mediterranean has been further implemented due to Athens' participation in the Olympic Games, infrastructure improvements, and the development of international airport investment. At the same time, we must focus on urban construction and avoid the disadvantages of urban growth caused by excessive expansion. At the same time, it affect future development prospects. Zhou [12] reports that most losses can be avoided by combining land. Since the assembly type is realized through the system, behind the seemingly successful land collection, the final public land collection is used to reduce market competition. Financial indicators have always been the object of research jointly pursued by economists in many countries. For example, in the study conducted by Thi et al. [13], financial indicators and the economy are often explored through people's happiness index, which is largely related to whether their lives are rich or not. In research carried out by Janina [14], it is said that the economic system of the EU member states has been practiced, which has played a good role as a reference for China's economic development. Always follow the European economy to become the world's first development goal. Frank and Pothen [15] explored the role of existing rules, which had a very positive impact on experimental data. It can be regarded as a satisfactory income-material use relationship. The results of the linear model of internal nonstationarity and nonstationarity in the materials used show that the elasticity of MF's income material is greater than that of DMC. Combining the abovementioned literature and considering the wide application of AHP, this study will use AHP in fuzzy evaluation to judge the economic quality in the economic supply structure, as well as the score of innovation and development, and identify existing problems after high-quality evaluation of economic development and also provide solutions and suggestions.

\section{Basic Indicators}

The AHP is one of the main analysis methods of global classic citations. When it solves some problems, it can give specific analysis steps and solution ideas, as shown in Figure 1.

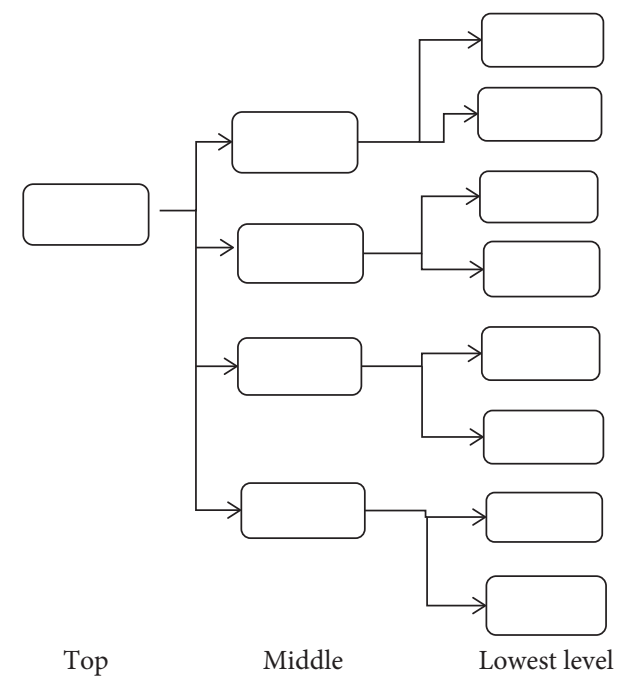

Figure 1: Schematic diagram of AHP.

The highest level is economic development quality $\mathrm{A}$ in Province $\mathrm{H}$, and the middle level is economic structure $B_{1}$, innovation efficiency $B_{2}$, green development $B_{3}$, social harmony $B_{4}$, and so on.

In contrast, the AHP has superior practicability, which stems from the simplification of the complex data processing by the AHP. In addition to the simple calculation, the required data will be less, and the problem will be quantified. Based on this, an evaluation of the level of high-quality economic development is carried out.

(1) Build a hierarchical structure model. Based on the research background and high-quality economic indicators, this study lists the high-quality of economic development as the highest level, with a total of 12 indicators from four aspects: economic structure construction, innovative development, green development, and social harmony. Build an evaluation index system for the level of economic development.

(2) Construct a judgment matrix at all levels. According to the existing searched information, it is further constructed by vectors $W, M$.

(3) Infer the maximum eigenvalue of the matrix $\lambda_{\max }$. Judging from the known conditions, the maximum eigenvalue and the standardized eigenvector $w$ are calculated. And make them consistent.

(4) Consistency inspection. To test whether the weights are valid, a consistency test is performed.

Methods are as follows:

$$
\begin{aligned}
C I & =\frac{\left(\lambda_{\max }-n\right)}{(n-1)}, \\
C R & =\frac{C I}{R I} .
\end{aligned}
$$


When the conditions $\lambda_{\max }=n, C I=0$ are met and the condition of the random consistency ratio is $C R<0.1$, the consistency test can be reached.

\section{Construction of the Evaluation Index Model}

3.1. Construction of Fuzzy Evaluation Index. Use a fuzzy evaluation model to construct multiple indicators. Construct the evaluation index set $U$ and the evaluation grade set $L$. The index evaluation grades will be evaluated by experts according to relevant standards and local average levels. Evaluation level set $L=(4,3,2,1,0)$ correspond to the excellent, good, general, qualified, and unqualified levels, respectively, refer to the Likert scale, which is divided into 5 numerical intervals, as shown in Table 1:

In Table 1, the division of grades is based on economic data in the process of economic development, and the hierarchical analysis of economic development through grades is measurable and operable.

Suppose $N$ experts give a grade evaluation $i$ to the index, and someone gives the grade $k$ to $N_{k}$. The degree of membership of the index is $r_{i k}=N_{i k} / N(i=1,2, \ldots, L ; k=1,2$, $3,4,5)$. The index's hierarchical membership matrix can be obtained as follows:

$$
R=\left[\begin{array}{c}
r_{11}, r_{12}, r_{13}, r_{14}, r_{15} \\
r_{21}, r_{22}, r_{23}, r_{24}, r_{25} \\
\ldots \\
r_{i 1}, r_{i 2}, r_{i 3}, r_{i 4}, r_{i 5}
\end{array}\right] .
$$

The following are the specific steps:

(1) Build a subtarget set $U=\left(U_{1}, U_{2}, U_{3}, U_{4}\right)$

(2) Determine the subgoal weight set according to the AHP as follows:

$$
P=\left(P_{1}, P_{2}, P_{3}, P_{4}\right)
$$

(3) Determine the weight set of each subtarget indicator using the following equation:

$$
W=\left(w_{1}, w_{2}, \ldots, w_{i}\right) \text {. }
$$

(4) The index is obtained according to the evaluation results of experts; the grade membership $i$ matrix $r_{i}$, which is as follows:

$$
r_{i}=\left(r_{i 1}, r_{i 2}, r_{i 3}, r_{i 4}, r_{i 5}\right), \quad i=1,2, \ldots, L .
$$

(5) The degree of membership is expressed as follows:

$$
A=w_{i} r_{i}
$$

(6) Get the comprehensive evaluation matrix of subgoals as follows:

$$
A_{U_{m}}=A_{U_{m} 1}, A_{U_{m} 2}, A_{U_{m} 3}, A_{U_{m} 4}, A_{U_{m} 5}(=1,2,3,4) .
$$

(7) Get the overall goal evaluation matrix $\mathrm{Du}$ as follows:
TABLE 1: Evaluation grades of high-quality economic development indicators.

\begin{tabular}{lccccc}
\hline $\begin{array}{l}\text { Evaluation } \\
\text { grade }\end{array}$ & Excellent & Good & Generally & Qualified & Unqualified \\
\hline $\begin{array}{l}\text { Digital } \\
\text { interval }\end{array}$ & {$[90,100]$} & $\begin{array}{c}{[70,} \\
90]\end{array}$ & {$[50,70]$} & {$[30,50]$} & {$[0,30]$} \\
$\begin{array}{l}\text { Average } \\
\text { value }\end{array}$ & 95 & 80 & 60 & 40 & 20 \\
\hline
\end{tabular}

$$
D_{U}=A P=\left(D_{1}, D_{2}, D_{3}, D_{4}, D_{5}\right)
$$

(8) Derive a set of scores which are shown as follows:

$$
B=(95,80,60,40,15) \text {. }
$$

(9) Finally, the overall economic growth can be calculated using the following equation:

$$
F=D_{U} \cdot B^{T}
$$

3.2. Use Dimensionless Processing of Data. If the research on a certain issue involves $k$ years, and if there are $m$ evaluated objects and $n$ basic indexes, these indexes can be arranged into time-comprehensive data according to the time under investigation. Suppose the basic index value matrix of the index system is as follows:

$$
\begin{aligned}
X=x_{i j}\left(t_{k}\right), & \\
& (i=1,2, \ldots n ; \quad j=1,2, \ldots m ; k=1,2, \ldots K) .
\end{aligned}
$$

(1) $x_{i j}\left(t_{k}\right)$ is the sample corresponds $i$ to the value of the index $j$ in the $k$ year. Let's denote $u_{i}$ as the specific name of the first sample $i$.

The formula for dimensionless processing is as follows:

$$
\begin{gathered}
y_{i j k}=\frac{x_{i j k}-x_{i j k}^{-}}{\sigma_{i j k}}, \\
i=1,2, \ldots m, \\
j=1,2,3, \ldots n, \\
k=1,2, \ldots K .
\end{gathered}
$$

After standardization $y_{i j k}$, then the $i$ sample corresponds to the index value $j$ of the $k$ year related to the index advancement. The index corresponds to $x_{i j k}^{-}$to the average value of the $k$ years, which is its standard deviation $\sigma_{\mathrm{ijk}}$.

Second, determine the index weight. Suppose the comprehensive evaluation function is as follows:

$$
z_{i}\left(t_{k}\right)=\sum_{j=1}^{n} \delta_{i} y_{i j}\left(t_{k}\right) .
$$

For the determination of indicator weights, the method of the sum of squares of total deviations is used to maximize the difference between each sample: 


$$
\sigma^{2}=\sum_{k=1}^{k} \sum_{i=1}^{m}\left(z_{i}\left(t_{k}\right)-\bar{z}\right)^{2}=\sigma^{t} \sum_{k=1}^{K} H_{k} \quad \delta=\delta^{T} H \delta .
$$

The known condition $\delta=\left(\delta_{1}, \delta_{2}, \ldots \delta_{n}\right)^{2}=\delta^{t} \sum_{k=1}^{K} H_{k}$ is a symmetrical rectangle. Then, $H_{k}=A_{k}^{T} A_{k} k=1$, $2, \ldots, K$. So when $\delta^{T} \delta=1$, the matrix $H$ takes the largest eigenvector, so $\sigma^{2}$ gets the maximum value.

(2) The basic principle of the EM evaluation model can be calculated by considering the nonrigid quantitative index data:

$$
v_{i j k}=\frac{y_{i j k}}{\sum_{i=1}^{m} y_{i j k}}
$$

$v_{i j k}$ is the target $j$ of the rating corresponding $i$ to the indicator and also corresponds to the characteristic weight of the $k$ year.

From this, calculate the EM value of the index item $j$, denoted as $E_{j k}$, which is as follows:

$$
E_{j k}=-\frac{1}{\ln (m)} \sum_{i=1}^{m} v_{i j k} \ln \left(v_{i j k}\right) \text {. }
$$

When $v_{i j k}=0$ or 1 , then $v_{i j k} \ln \left(v_{i j k}\right)=0$, then the coefficient of difference $D_{j k}$ is as follows:

$$
D_{j k}=1-E_{j k} \text {. }
$$

The larger the indicator $D_{j k}$, the clearer the data of the object being evaluated $j$, and the greater the weight, so this indicator is more important in the evaluation system. From this, the EM weight of the indicator can be determined as follows:

$$
w_{j k}=\frac{D_{j k}}{\sum_{j=1}^{n} D_{j k}}
$$

Because the EM evaluation in the abovemenitioned model does not depend on the distribution of the data, it is concluded that the evaluation model of AHP is relatively stable, and the comprehensive evaluation result measured by this model can more scientifically reflect the true level of the evaluation object.

\section{Empirical Simulation}

A provincial-level city $\mathrm{H}$ in the central and eastern regions is selected as the research sample. Its economic development level has obvious high-quality characteristics, but some of the cities have relatively average development levels. The aim is to improve the feasibility of the research through the empirical analysis of this article and also to provide a certain theoretical reference for economic development evaluation.

4.1. Determine the Index Weight. Three economics professors $(k=1,2,3)$ and industry experts were invited to evaluate the high-quality economic development indicators of $Z$ Province. The evaluation weights of experts are set to $(0.5$,
TABle 2: Reciprocal judgment matrix of the $N_{1}, N_{2}, N_{3}$ expert's general goal A.

\begin{tabular}{lcccc}
\hline $\mathrm{A}$ & $B 1$ & $B 2$ & $B 3$ & $B 4$ \\
\hline$B 1$ & 1 & 2 & 3 & 4 \\
$B 2$ & 0.5 & 1 & 2 & 3 \\
$B 3$ & 0.33 & 0.5 & 1 & 2 \\
$B 4$ & 0.25 & 0.3 & 0.5 & 1 \\
\hline
\end{tabular}

0.3 , and 0.2 ). The first-level evaluation indicators made by the three related experts on the highest level A are as shown in Tables 2.

According to the weights calculated by the existing indicators, the weight vector of $\mathrm{A}$ is derived from the known first-level indicator B.

$$
\begin{aligned}
& W_{1}=(0.4676,0.2773,0.1598,0.0953) \\
& W_{2}=(0.5636,0.2573,0.1094,0.0697) \\
& W_{3}=(0.5040,0.3005,0.1224,0.0732)
\end{aligned}
$$

Comprehensive opinions are available, which are as follows:

$$
\begin{aligned}
& W=0.5 W_{1}+0.3 W_{2}+0.2 W_{3}=(0.50368, \quad 0.27594, \\
& 0.1372,0.0832)
\end{aligned}
$$

According to the index weights obtained, the corresponding weights of each three-level index and the secondlevel index can be comprehensively obtained, as shown in Table 3 of the specific courseware.

It can be seen that the graded membership evaluation matrix of the three-level indicators corresponding to innovation efficiency face-to-face and the three-level indicator grade membership evaluation matrix in terms of economic structure, green development, and social harmony can be obtained $M_{B_{2}}, M_{B_{3}}, M_{B_{4}}$ in the same way, which is as follows:

$$
\begin{aligned}
& M_{B_{1}}=\left[\begin{array}{ccccc}
0.375 & 0.525 & 0.1 & 0 & 0 \\
0.1 & 0.625 & 0.1 & 0.1 & 0 \\
0.1 & 0.225 & 0.4 & 0.175 & 0 \\
0.225 & 0.5 & 0.2 & 0.025 & 0
\end{array}\right], \\
& M_{B_{2}}=\left[\begin{array}{ccccc}
0.3 & 0.45 & 0.15 & 0.05 & 0 \\
0 & 0.35 & 0.4 & 0.25 & 0 \\
0.1 & 0.375 & 0.3 & 0.225 & 0 \\
0 & 0.135 & 0.425 & 0.45 & 0 \\
0 & 0.2 & 0.55 & 0.25 & 0 \\
0.1 & 0.25 & 0.45 & 0.3 & 0
\end{array}\right], \\
& M_{B_{3}}=\left[\begin{array}{ccccc}
0.275 & 0.625 & 0.1 & 0 & 0 \\
0.1 & 0.425 & 0.175 & 0.3 & 0 \\
0.5 & 0.35 & 0.15 & 0 & 0 \\
0.55 & 0.275 & 0.175 & 0 & 0
\end{array}\right], \\
& M_{B_{4}}=\left[\begin{array}{ccccc}
0 & 0.2 & 0.55 & 0.25 & 0 \\
0.1 & 0.15 & 0.5 & 0.25 & 0 \\
0.3 & 0.45 & 0.25 & 0 & 0 \\
0.125 & 0.25 & 0.525 & 0.1 & 0
\end{array}\right] .
\end{aligned}
$$


TABLE 3: Index weights of the evaluation index system.

\begin{tabular}{|c|c|c|c|c|c|}
\hline First level indicator & Weights & Secondary indicators & Weights & Three-level indicators & Weights \\
\hline \multirow{4}{*}{ Economic structure } & \multirow{4}{*}{0.50368} & \multirow{2}{*}{ Industrial structure } & \multirow{2}{*}{0.5} & Proportion of secondary production & 0.1771 \\
\hline & & & & Proportion of tertiary industry & 0.1145 \\
\hline & & \multirow{2}{*}{ Open to the outside world } & \multirow{2}{*}{0.5} & Total imports and exports accounted for GDP & 0.3542 \\
\hline & & & & Foreign trade dependence & 0.3542 \\
\hline \multirow{3}{*}{ Innovation efficiency } & \multirow{3}{*}{0.27594} & \multirow{2}{*}{ Industrial innovation } & \multirow{2}{*}{0.5} & TFP & 0.0969 \\
\hline & & & & GDP energy consumption & 0.1654 \\
\hline & & Technological innovation & 0.5 & Increased proportion of technology industry & 0.1954 \\
\hline \multirow{3}{*}{ ECO development } & \multirow{3}{*}{0.1372} & Air guality & 05 & Good air quality rate & 0.1176 \\
\hline & & A1 & 0.5 & Urban vegetation coverage & 0.1643 \\
\hline & & Governance level & 0.5 & Environmental protection investment index & 0.2613 \\
\hline \multirow{2}{*}{ Social harmony } & \multirow{2}{*}{0.0832} & Citizens' lives & 0.5 & Gini index & 0.3159 \\
\hline & & Social security & 0.5 & Social satisfaction index & 0.2153 \\
\hline
\end{tabular}

TABLE 4: Evaluation results of economic innovation and development in $\mathrm{H}$ Province.

\begin{tabular}{lccccc}
\hline Evaluation index & Excellent & Good & Generally & Qualified & 0 \\
\hline TFP & 0.375 & 0.525 & 0.1 & 0.1 & 0 \\
GDP energy consumption & 0.175 & 0.625 & 0.1 & 0.175 & 0 \\
Import for GDP & 0.1 & 0.225 & 0.4 & 0.2 & 0.025 \\
Industry increase rate & 0.225 & 0.55 & & 0 \\
\hline
\end{tabular}

4.2. Index Level Membership. After the questionnaire survey, we asked experts for detailed evaluation opinions on the economic quality growth indicators of $\mathrm{H}$ Province. The evaluation results are shown in Table 4 and in Figure 2.

4.3. Evaluation and Analysis of Index Results. The comprehensive evaluation result $M$ and the index weight $W$ are based on the maximum degree of membership, and then the evaluation of the economic development results of $H$ Province and the evaluation of the overall development results are obtained:

$R_{1}=W_{B_{1}} \bullet M_{B_{1}}=(0.1930,0.4047,0.2417,0.0823,0)$, the economic structure of $\mathrm{H}$ Province is well developed, with a level of membership of $40.47 \%$

$R_{2}=W_{B_{2}} \bullet M_{B_{2}}=(0.0746,0.2873,0.3970,0.2623,0)$, the development of innovation efficiency is average, with a level of membership of $28.73 \%$.

$R_{3}=W_{B_{3}} \bullet M_{B_{3}}=(0.3208,0.4410,0.1479,0.0903,0)$, the development of green development is in good condition, with a grade affiliation of $44.10 \%$.

$R_{4}=W_{B_{4}} \bullet M_{B_{4}}=(0.1200,0.2487,0.4653,0.1660,0)$, the development of social harmony is average, with a level of membership of $46.53 \%$.

$$
\begin{aligned}
F & =R \bullet B^{T}=W \bullet\left(R_{1} R_{2} R_{3} R_{4}\right)^{T} \bullet B^{T}, \\
& =(0.1719,0.3644,0.2902,0.1399,0) \cdot(95,80,60,40,15), \\
& =68.4905 .
\end{aligned}
$$

In summary, the overall economic quality development of $\mathrm{H}$ Province is subordinate to "excellent, good, general, qualified, and unqualified" with a degree of 68.4905 , which shows that under the

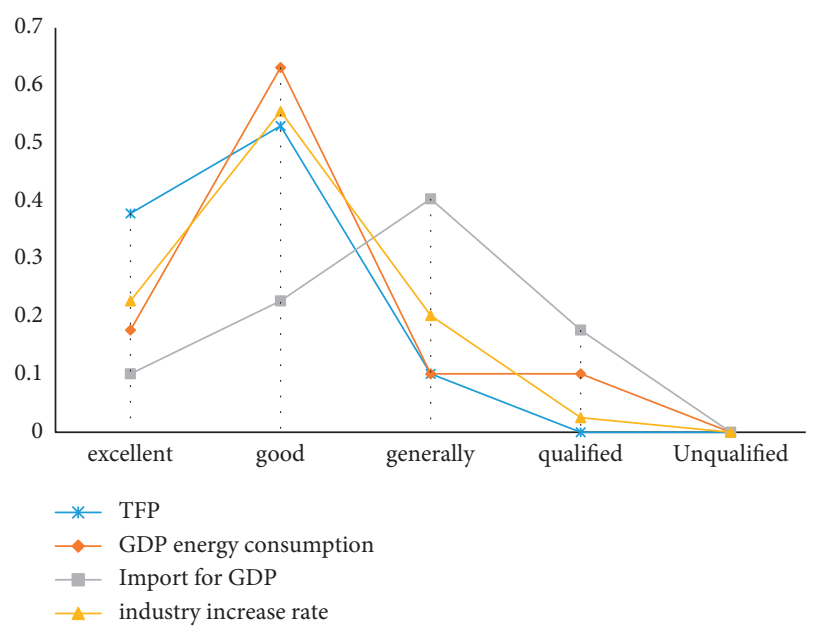

FIgURE 2: Evaluation results of economic innovation and development in H Province.

evaluation system of high-quality economic development, the economic development of $\mathrm{H}$ Province is at its best when the higher level of the general level tends to be good, and the indicators basically meet the national standards, but the ratings for green development and social harmony are low, indicating that the province may have insufficient resource allocation optimization problems. In the future, enterprises in the province may consider introducing and optimizing the AHP system to improve the operating efficiency of enterprises in the province and contribute to the high-quality development of China's economy.

4.4. Introduce Entropy Method to Analyze. The entropy method is used to analyze the high quality of the economy of $\mathrm{H}$ Province and assign values and standardize the selected values and standardize the positive indicators. 
TABle 5: Measurement results of high-quality development of some city in H Province.

\begin{tabular}{lcccccccccccc}
\hline \multirow{2}{*}{ Years } & \multicolumn{2}{c}{ B city } & \multicolumn{2}{c}{ C city } & \multicolumn{2}{c}{ D city } & \multicolumn{2}{c}{ E city } & \multicolumn{2}{c}{ F city } & \multicolumn{2}{c}{ G city } \\
& Index & Rank & Index & Rank & Index & Rank & Index & Rank & Index & Rank & Index & Rank \\
\hline 2013 & 0.314 & 6 & 0.515 & 1 & 0.399 & 2 & 0.374 & 3 & 0.358 & 5 & 0.367 & 4 \\
2014 & 0.311 & 6 & 0.531 & 1 & 0.398 & 3 & 0.410 & 2 & 0.377 & 4 & 0.356 & 5 \\
2015 & 0.357 & 6 & 0.549 & 1 & 0.421 & 3 & 0.428 & 2 & 0.419 & 4 & 0.389 & 5 \\
2016 & 0.370 & 6 & 0.580 & 1 & 0.472 & 3 & 0.481 & 2 & 0.457 & 4 & 0.434 & 5 \\
2017 & 0.436 & 6 & 0.594 & 1 & 0.518 & 3 & 0.521 & 2 & 0.512 & 4 & 0.464 \\
2018 & 0.458 & 6 & 0.600 & 1 & 0.515 & 4 & 0.541 & 2 & 0.527 & 3 & 0.475 & 5 \\
\hline
\end{tabular}

$$
\begin{aligned}
& x_{i j}=\left(x_{i j}-\min x_{j}\right) /\left(\max x_{j}-\min x_{j}\right), \\
& x_{i j}=\left(\max x_{j}-x_{i j}\right) /\left(\max x_{j}-\min x_{j}\right),
\end{aligned}
$$

where standardize negative indicators $x_{i}$ represents the sample $i, x_{j}$ represents the index $j, \max x_{j}$ represents the maximum value obtained by the first indicator in 2013-2018, and $\min x_{j}$ represents the minimum value obtained by the first indicator in 2013-2018.

Taking into account various indicators of enterprise development in $\mathrm{H}$ Province, such as product sales, GDP energy consumption, completion of foreign economic and trade, and social insurance coverage, the statistics of $\mathrm{H}$ Province from 3013 to 2018 are shown in Table 5 .

From this, we can see the development trend of highquality economic development in cities in Province $\mathrm{H}$. The overall high-quality economic development shows an upward trend. The trend of high-quality economic development is shown in Figure 3.

Province $\mathrm{H}$ is a coastal province in the central and eastern regions, cities $\mathrm{C}, \mathrm{D}, \mathrm{E}, \mathrm{F}$, and $\mathrm{G}$ are all coastal cities, and $\mathrm{B}$ becomes a central city. In recent years, the highquality economic development of cities in $\mathrm{H}$ Province has been on an upward trend year by year. The economic development level is ranked by $\mathrm{C}$ city, $\mathrm{E}$ city, $\mathrm{D}$ city, F city, G city, B city, and so on. C city has relatively good infrastructure and has advantages in all aspects of technological and economic development. Compared with the location of $\mathrm{B}$ city in the middle, the development slightly lags behind other cities.

Due to the use of the entropy method to consider the selected indicators in $\mathrm{H}$ Province as detailed as possible, the high-quality economic development has also been reflected to a certain extent, but the AHP analysis method is more suitable for classification and qualitative and quantitative treatment of problems. It also reflects that this applicability is more stable to a certain extent.

4.5. Analysis and Research on the Level of High-Quality Economic Development. This study combines the economic development status of the central, western, and eastern cities as the research object, and the data and time span of the investigation are concentrated in 2013-2018 through relevant data websites for scientific statistics. This study uses 2010 as the base for reference, according to statistical analysis. It is shown in Table 6.

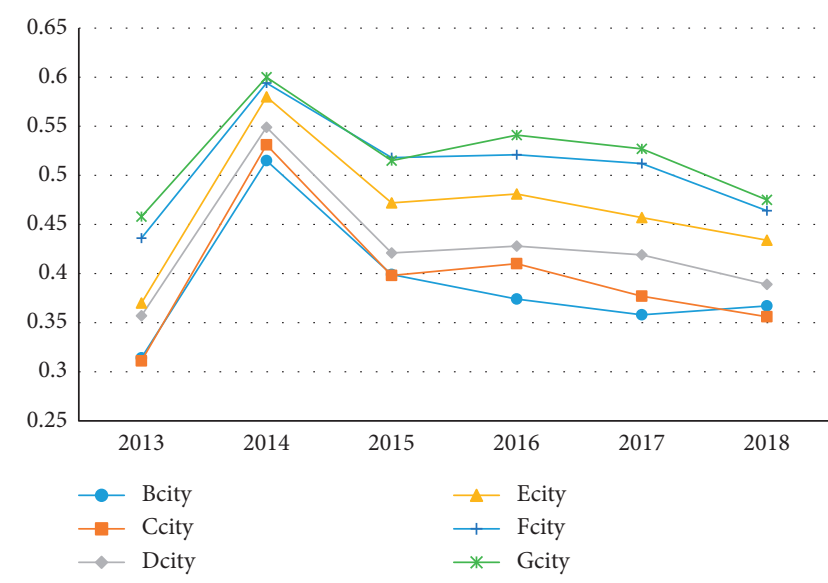

FIGURE 3: Measurement results of high-quality development of some cities in $\mathrm{H}$ Province.

The results show that the high-quality economic development of most provinces has been greatly improved. Thanks to the strong support of policies and the independent consciousness of innovation in most provinces, economic development has taken a great leap. Compared with 2013, the provinces in different ranks showed a slight fluctuation trend in 2018, but the provinces with the top ranks are always in the east. Therefore, the development quality time evolution of the main regions in the country is divided, and the average scores of the three major regions are obtained, as shown in Figure 4.

Figure 4 shows that during the inspection period, the high-quality economic development of the eastern region fluctuates cyclically, which is always higher than that of the central and western regions. The development trend of cities in the central region is showing signs of decline. The highquality economic development of the western region has been lower than that of the central region in most years, but it has a slow-climbing characteristic, and the development gap with the central region has been narrowing. It shows that during this period of time, with the policy support of the 18th National Congress of the Communist Party of China, the level of economic development in the western region has been effectively improved.

Analyze the gradual trend of the high-quality economic development level according to the coefficient of variation of the difference, as shown in Figure 5.

The balance of the high-quality economic coefficient of variation is between 0.34 and 0.37 . In 2013, it was even $4.7 \%$ 
TABLE 6: Average and ranking of regional economic quality development level.

\begin{tabular}{lcccccccccccc}
\hline Area & 2013 & Rank & 2014 & Rank & 2015 & Rank & 2016 & Rank & 2017 & Rank & 2018 & Rank \\
\hline Central & 3.95 & 2 & 3.98 & 2 & 3.90 & 2 & 3.94 & 2 & 3.91 & 2 & 3.92 & 2 \\
West & 3.9 & 3 & 3.88 & 3 & 3.87 & 3 & 3.89 & 3 & 3.88 & 3 & 3.92 & 2 \\
East & 4.14 & 1 & 4.15 & 1 & 4.2 & 1 & 4.17 & 1 & 4.19 & 1 & 4.12 & 1 \\
\hline
\end{tabular}

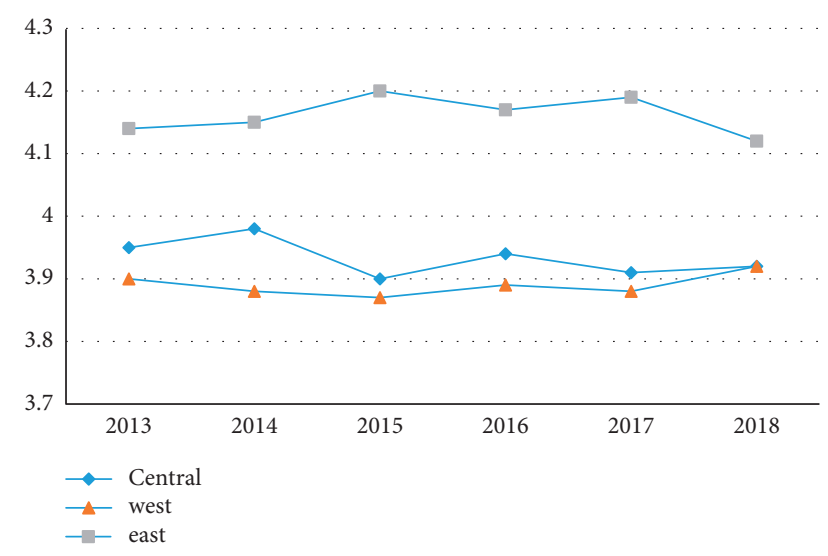

FIgURE 4: The time evolution of high-quality economic development in China's three major regions from 2013 to 2018.

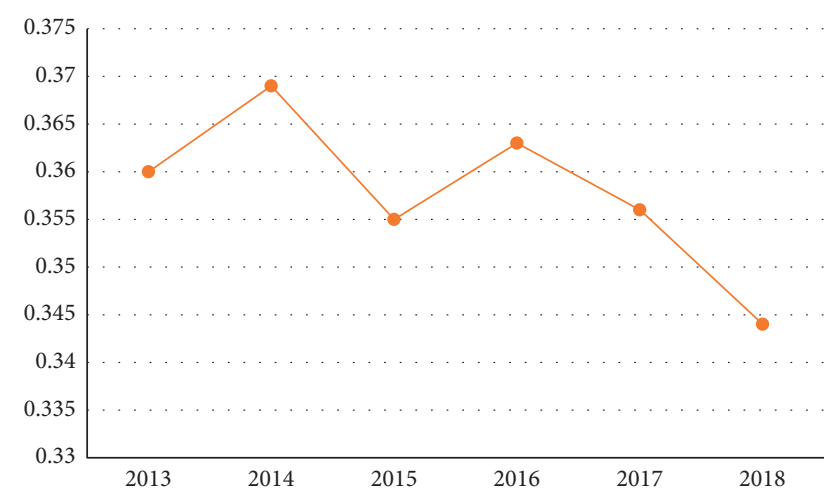

Figure 5: The gradual process of the development of my country's economic quality differentiation from 2013 to 2018.

higher than that in 2018. This indicates that the gap in my country's high-quality economic development has narrowed to a certain extent after the 18th National Congress of the Communist Party of China, but the gap still exists.

According to the level of economic development from 2013 to 2018, their basic statistics and the box-line chart of economic development scores are obtained, as shown in Table 7 and Figure 6, respectively.

In general, from 2013 to 2018, the economic growth level showed a trend of volatility and decline. Compared with 2013, the national economic growth level in 2018 declined as a whole, the distribution of scores was more scattered, and the gap in economic growth levels between regions increased. After reaching the maximum level of economic growth in 2015 and the smallest gap between regions, the average, median, and minimum economic growth level scores all showed a downward trend, while the maximum level of economic growth has been increasing, indicating
TABLE 7: Statistics related to the level of economic growth.

\begin{tabular}{lcccccc}
\hline & 2013 & 2014 & 2015 & 2016 & 2017 & 2018 \\
\hline Max & 78.30 & 73.14 & 64.88 & 83.79 & 89.61 & 97.11 \\
Minimum & 13.40 & 15.58 & 14.93 & 12.83 & 11.10 & 0.36 \\
Mean & 27.53 & 30.21 & 31.78 & 29.54 & 27.79 & 25.17 \\
Median & 22.21 & 25.95 & 29.96 & 23.77 & 20.05 & 16.89 \\
\hline
\end{tabular}

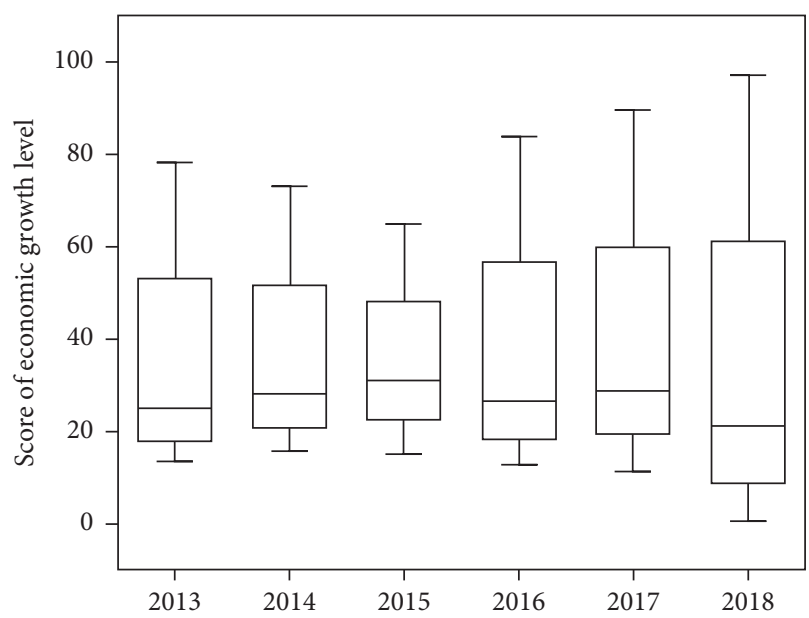

Figure 6: Box-line diagram of economic development score.

that with some developed regions with the increase in economic growth, the economic growth rate of most regions is declining, and the growth rate of factory output is too slow. The gap between their economic growth level and the current optimal economic growth level is getting larger and larger, resulting in a gradual decrease in their economic growth scores. This is also a manifestation of the widening gap in the level of economic growth between regions.

\section{Conclusion}

Combining Province $\mathrm{H}$ as the research object of high-quality economic development, the problems are exposed in this experiment. The economic structure is relatively healthy and high-level development level, but the innovative development is slightly inferior to the economic structure, but it is still a leading level in the country. As a result, green development and social harmony have highlighted problems. Urban construction is inseparable from green coverage, scientific and healthy development planning, and taking into account the happiness of the people. Environmental factors are also the primary consideration for development. The following suggestions are put forward in this study: all regions should strengthen exchanges and cooperation, and those with relatively backward development should actively 
strengthen inspections and learning; strengthen the awareness of ecological protection and actively adopt new technologies and new energy to keep green water and green mountains; be aware of strengthening the economy. The concept of synergistic growth and high-quality development should fully recognize that economic growth is the material basis for high-quality economic development. On the basis of ensuring the existing economic growth results, we must pay attention to gradually promoting a high-quality economy in all aspects and multiple fields. To improve the uneven development in the past, we should formulate a more scientific strategy with strong support from the government, make full use of existing resources, strengthen unity and cooperation between provinces, and jointly promote highquality economic development, revitalize China, and achieve generalization. The Chinese dream of the masses.

\section{Data Availability}

The experimental data used to support the findings of this study are available from the corresponding author upon request.

\section{Conflicts of Interest}

The author declares no conflicts of interest.

\section{References}

[1] M. Yaksic, "Inclusive system for sustainable economic development," Journal of Central Banking Theory and Practice, vol. 7, no. 1, pp. 5-16, 2018.

[2] A. Nekrep, S. Strašek, and D. Boršič, "Productivity and economic growth in the EU: the impact of R\&D investment," Nase Gospodarstvo/Our Economy, vol. 64, no. 1, pp. 18-27, 2018.

[3] J. Lezgovko and A. Lezgovko, "The impact of service clusters on sustainable economic development," Economy and Culture, vol. 15, no. 2, pp. 75-87, 2018.

[4] J. Tsaurai and A. N. Do, "Infrastructure human capital development and economic growth in transition countries," Comparative Economic Research, vol. 22, no. 1, pp. 33-52, 2019.

[5] K. Tsaurai, "Personal remittances, banking sector development and economic growth in Israel: a trivariate causality test," Corporate Ownership and Control, vol. 13, no. 1, pp. 806-819, 2015.

[6] W. Douglas and L. Muller, "Evaluation of urban competitiveness in urban areas of developing countries," The Way Forward, vol. 17, 2000.

[7] S. Zanakis and I. Becerra-Fernandez, "Competitiveness of nations: a knowledge discovery examination," European Journal of Operational Research, vol. 166, no. 1, pp. 185-211, 2005.

[8] B. Paul and H. Gert-Jan, "Urban knowledge competitiveness economy: university as a new planning animator," Planning Progress, vol. 67, no. 2, pp. 105-197, 2007.

[9] R. J. Barro, "Quantity and quality of economic growth," Central Bank of Chile, vol. 6, pp. 135-162, 2002.

[10] M. Mlachila, R. Tapsoba, and S. J. A. Tapsoba, "Growth quality index countries in developing countries: proposals," Social Indicators Research, vol. 134, no. 2, pp. 675-710, 2017.
[11] I. Chorianopoulos, T. Pagonis, S. Koukoulas, and S. Drymoniti, "Planning, competitiveness and sprawl in the Mediterranean city: the case of Athens," Cities, vol. 27, no. 4, pp. 249-259, 2010.

[12] X. L. Zhou, "The analysis of the investigation on word combinations at undergraduate level of overseas students taking SISU as an example," The Journal of Chinese Language and Literature, vol. 75, no. 8, pp. 263-297, 2012.

[13] D. Thi, T. Van, and H. Nguyen, "Linh. The impact of inclusive finance on economic development: taking Asia-Pacific countries as an example," Comparative Economic Research, vol. 22, no. 1, pp. 7-16, 2019.

[14] G. V. Janina, "The contribution of social economy to economic development," Journal of Timisoara Economics and Business, vol. 11, no. 2, pp. 121-134, 2018.

[15] P. Frank and W. Heinz, "Economic development and material utilization. Evidence from international panel data," World Development, vol. 115, pp. 107-119, 2019. 